\title{
Risk Analysis and Countermeasures of Cross Border e-Commerce Projects Between China and the United States During the Game Period
}

\author{
Chen tiequan ${ }^{1, \mathrm{a}}$ * \\ ${ }^{1}$ Graduate School of Liaoning University of Technology, Guta, JinZhou, Liaoning, China \\ ${ }^{2}$ Liaoning Finance Vocational College, Shenbei, Shenyang, Liaoning, China \\ ${ }^{a * 16338514 @ q q . c o m}$
}

\begin{abstract}
Trade friction between China and the United States has a huge impact on the development of cross-border e-commerce in China, the complexity of cross-border e-commerce business and the uncertainty of Sino-US trade relations make opportunities and risks coexist for a long time. Against the background of the current Sino-US relations, this paper identifies risks through the establishment of risk lists by cross-border e-commerce enterprises, and uses the risk evaluation system to analyze and evaluate risks, expert assessment of overall risk, research on risk management of sino-US cross-border e-commerce projects by developing risk response plans to avoid risks, through research, cross-border e-commerce enterprises attach importance to risk management, establish risk awareness, build an overall and systematic risk management system, and run risk management throughout cross-border e-commerce projects.
\end{abstract}

Keywords: Cross-border e-commerce, risk, brain storm method, Analytic hierarchy

\section{中美博弯期两国跨境电商项目风险分析及对策 陈铁权}

${ }^{1}$ 辽宁工业大学研究生院, 古塔, 锦州, 辽宁, 中国

${ }^{2}$ 辽宁金融职业学院, 沈北, 沈阳, 辽宁, 中国

a*16338514@qq.com

\section{摘要}

中美之间的贸易摩擦对中国跨境电商的发展造成了巨大的冲击, 跨境电商业务的复杂性和中美两国贸易关系的 不确定性使跨境电商行业机遇和风险长期并存。以当前中美关系为大背景, 通过跨境电商企业建立风险清单识 别风险, 利用风险评价体系分析评估风险, 专家打分评价总体风险, 制定风险应对计划规避风险几个过程对中 美跨境电商项目展开风险管理研究, 通过研究使跨境电商企业重视风险管理, 建立风险忧患意识, 构建整体的、 系统的风险管理体系，将风险管理贯穿于跨境电商项目始终。

关键词: 跨境电商, 风险，头脑风暴法，层次分析法

\section{1. 前言}

随着互联网技术的飞速发展, 全球互联网用户数 量在近 10 年间呈现持续高速增长的趋势, 根据互联 网世界统计 (IWS) 的数据显示, 截至 2020 年 5 月 31 日, 全球互联网用户占世界人口的比重达到 59.6\%, 数量突破 46.48 亿人。互联网用户的快速增长和信息 通信技术的创新推动了传统贸易模式的升级改造, 跨
境电子商务交易平台、智慧物流系统、货物进出关智 能监管等新模式和业态促进了跨境电子商务 (以下简 称 “跨境电商”) 的井喷式发展, 为跨境电商注入了 新的活力。根据《2020-2026 年中国电子商务行业发 展模式分析及投资风险研究报告》的数据显示, 全球 跨境电商市场规模将从 2018 年的 6750 亿美元增长到 2020 年的 9940 亿美元，年平均增速近 30\%，远超传 统贸易增速。中国的跨境电商交易规模从 2017 年的 
7.5 万亿人民币到 2020 年预计增至 12 万亿人民币, 三年复合增长率为 $16.44 \%$, 与发达国家相比, 中国 作为发展中国家，跨境电商市场规模相对均衡，具有 极高的增长潜质, 发展潜力巨大。美国是西方最主要 的发达经济体, 电子商务服务体系发展成熟、发展环 境极佳，中美之间多年来一直互为主要贸易伙伴，经 贸合作是两国合作的基础和核心点，2019 年前 11 个 月，中美间贸易总额达 3.4 万亿人民币，虽然中美间 贸易摩擦导致两国贸易总额与同期相比下降 $11.1 \%$, 但两国间互为主要贸易伙伴的关系和地位并未改变。 [1]

跨境电商全球化的发展趋势和中国电商行业的 迅猛发展给中国跨境电商行业带来了巨大的机遇, 2020 年 1-9 月份, 中国跨境电商零售额继续保持 $52.8 \%$ 的高速增长, 但同时, 中美之间的贸易摩擦对中国跨 境电商的发展也造成了巨大的冲击, 中美两国间针锋 相对的贸易竞争使中国跨境电商行业 “唇亡齿寒” , 跨境电商业务的复杂性和中美两国贸易关系的不确 定性使跨境电商行业机遇和风险长期并存。虽然, 中 国政府在政策体系、创新商业模式、海外仓建设、深 化国际合作等方面不断为跨境电商发展提供新空间、 新动能, 但跨境电商项目仍存在诸如高关税、结算周 期长等不确定风险, 而对于中美跨境电商风险分析及 防范问题, 学术界和实务界还缺少关注和研究。

\section{2. 文献回顾与问题提出}

跨境电子商务学术界迄今为止还没有给出统一 的概念, 通过文献检索和搜索引擎检索, 整理搜索结 果后可将跨境电商定义归纳为: 全球的企业和个人通 过电子商务平台进行商品展示推广、交易协商、建立 货物订单、在线支付与结算、跨境物流追踪与运输、 商品售后与纠纷处置, 实现跨境交易的一种国际商业 活动。

国内外众多的研究表明: 虽然跨境电商项目市场 需求旺盛, 跨境电商企业专业化程度越来越高, 但跨 境电商企业之间竞争激烈, 跨境电商交易中间环节较 多, 同时, 跨境电商企业极易受国内外多重环境影响、 制约, 跨境电商项目将长期处于机遇与风险并存状态。 虽然研究者对跨境电商项目的风险进行过大量的识 别并进行定量分析, 取得了丰硕的研究成果, 但从研 究的成果来看, 研究的结果对跨境电商的风险认识缺 少全面性, 风险分析过程缺少系统性。居永梅 (2020) 用层次分析法对跨境电商在第三方物流选择上的风 险做了识别与评估 ${ }^{[2]}$ 。刘益灯 (2020) 认为跨境电商 面临众多商务纠纷的风险, 参与者应在充分了解法律 规定的基础上稳妥参与跨境电商交易 ${ }^{[3]}$ 。陈钰芬 (2019) 建立跨境电商商品质量风险评估系统并进行 实证研究, 提出了相关政策建议 ${ }^{[4]}$ 。王聪等 (2019) 通过借鉴国外先进经验并通过大数据风险分析对跨 境电商检疫风险管理进行了比较研究 ${ }^{[5]}$ 。薛朝改 （2019）运用社会网络分析法识别出影响跨境电商生 态系统的风险要素 ${ }^{[6]}$ 。
上述文献从跨境电商第三方物流、法律法规、商 品质量、风险检疫、生态环境等方面分析评估了跨境 电商面临的风险, 研究范围存在局限性, 未能与时俱 进的对跨境电商风险进行剖析, 缺乏先进性。基于相 关研究的局限性, 本文以当前中美关系为大背景, 通 过跨境电商企业建立风险清单识别风险, 利用风险评 价体系分析评估风险, 通过专家打分评价总体风险, 制定风险应对计划规避风险几个过程对中美跨境电 商项目展开风险管理研究, 通过研究使跨境电商企业 重视风险管理, 建立风险忧患意识, 构建整体的、系 统的风险管理体系, 将风险管理贯穿于跨境电商项目 始终。

\section{3. 中美博栾期跨境电商企业风险清单建立过 程}

自 2017 年以来，中国的崛起引发美国的强烈的 关注和担忧，美国一系列对华政策的出台使中美关系 发生重大变化, 中美关系跌至中美建交以来的最低谷, 与以往政冷经热的中美关系不同，此次中美间的博栾 直接从贸易战开始，对两国间的进出口贸易活动影响 巨大，虽然中美两国博弯日酣，但作为世界第一大经 济体的美国和第二大经济体的中国，两国相互间的贸 易关系一直都是你中有我，我中有你，两国间贸易不 可能完全脱钩, 完全抛弃彼此, 因此中美间的跨境电 商贸易仍具有巨大的市场开发潜力。

作为成熟的跨境电商企业，应善于利用有效的技 术方法识别、量化风险、管理风险、规避和利用风险, 在企业对风险的识别过程中，风险清单和头脑风暴法 常互相配合为企业识别出高优先级风险。企业风险清 单列示了企业经营各环节所面临的各种风险, 包括已 知和潜在分险、积极和消极的风险, 风险清单的内容 通常基于类似的、历史的项目，是风险识别的工具和 技术，风险识别的同时也对风险清单进行更新，对风 险描述进行改善。头脑风暴法通过专家会议激发与会 专家的创造性思维，专家通过在会议上的相互交流、 相互补充产生激发效应, 对于研究资料少、未知因素 多的风险识别, 结果更为精确。此轮中美间博弯始于 2017 年, 距今只有四年时间, 学术界和实务界对此 方面的研究成果较少，美国在此期间仍不断的对中国 进行政治挑眫和贸易制裁，为原本乌云密布的中美关 系增加了众多的不确定性因素，基于上述原因，对中 美间跨境电商风险的识别适合采用头脑风暴法，利用 头脑风暴法进行风险识别通过以下过程完成。

首先, 确定参加头脑风暴会议的专家人选。邀请 参会专家人数 10 至 15 人为宜, 专家研究领域包括: 跨境电商、国际贸易、国际工程管理、国际关系领域, 其中学术型和实务型专家各占一半。

其次，收集会议讨论的相关资料。会议召开前通 知参会专家会议议题并保证专家有充分时间搜集整 理相关信息, 相关研究指出, 相关信息收集越全面和 处理的越科学, 人们能识别出的项目风险就越全面, 
人们制定的项目风险应对和监控措施就越得当 ${ }^{[7]}$ 。

最后，制定会议原则，召开会议。会议应遵循以 下原则进行：

（1）会议目标集中，围绕目标提出尽可能多的 设想, 畅所欲言。

(2) 会议过程中不对别人意见和观点进行评价, 鼓励利用和改善别人的观点提出新的设想。

(3) 参会专家身份平等, 会议组织者平等对待 每一条设想, 所有设想必须无差别的被记录, 提倡自 由发言但禁止私下交流, 不干扰别人思维, 防止多数 意见阻碍个人观点的产生。

通过头脑风暴法对风险进行识别, 并对照以往企 业风险清单最终建立跨境电商风险识别指标体系, 识 别出的主要风险分类为政治风险、疫情风险、经济风 险、技术风险、管理风险、产品风险和市场风险等, 其中在现阶段的政治风险和疫情风险分类中专家总 结识别出新的风险指标, 应做为高优先级风险管理, 需要重点关注和制定出新的风险管理对策, 其余风险 分类归纳为常规风险, 有完整、成熟的风险应对措施, 做为一般风险管理。最终识别建立的政治风险和疫情 风险分类清单如表 1 所示, 其余常规风险未列示。

表 1 中美跨境电商风险清单

\begin{tabular}{|c|c|c|}
\hline $\begin{array}{l}\text { 一级 } \\
\text { 风险 }\end{array}$ & $\begin{array}{l}\text { 二级 } \\
\text { 风险 }\end{array}$ & 风险描述 \\
\hline \multirow{6}{*}{$\begin{array}{l}\text { 政治 } \\
\text { 风险 }\end{array}$} & $\begin{array}{l}\text { 关税 } \\
\text { 范围 } \\
\text { 扩大 } \\
\text { 风险 }\end{array}$ & $\begin{array}{l}\text { 中美两国相互扩大商品征税范围, 导 } \\
\text { 致商品价格上涨。 }\end{array}$ \\
\hline & $\begin{array}{l}\text { 清关 } \\
\text { 难度 } \\
\text { 增加 } \\
\text { 风险 }\end{array}$ & $\begin{array}{l}\text { 贸易战使中美两国海关加大了进出口 } \\
\text { 商品的核查力度, 对商品相关批文的 } \\
\text { 核查更加严格。 }\end{array}$ \\
\hline & $\begin{array}{l}\text { 电商 } \\
\text { 平台 } \\
\text { 政策 } \\
\text { 收紧 } \\
\text { 风险 }\end{array}$ & $\begin{array}{l}\text { 贸易战使中美两国政府对跨境电商政 } \\
\text { 策进一步收紧, 跨境电商平台管理更 } \\
\text { 加严格、规范。 }\end{array}$ \\
\hline & $\begin{array}{l}\text { 知识 } \\
\text { 产权 } \\
\text { 侵权 } \\
\text { 风险 }\end{array}$ & $\begin{array}{l}\text { 美国一向重视保护本国的知识产权, } \\
\text { 针对中国商品的知识产权检查格外严 } \\
\text { 格。 }\end{array}$ \\
\hline & $\begin{array}{l}\text { 中国 } \\
\text { 产品 } \\
\text { 信任 } \\
\text { 危机 } \\
\text { 风险 }\end{array}$ & $\begin{array}{l}\text { 美国政府不断宣扬中国威胁论, 鼓动 } \\
\text { 美国内和美盟友抵制中国商品。 }\end{array}$ \\
\hline & $\begin{array}{l}\text { 货物 } \\
\text { 第三 } \\
\text { 国转 }\end{array}$ & $\begin{array}{l}\text { 跨境电商企业通过第三方国家转口方 } \\
\text { 式逃避高额关税, 避税同时带来其他 }\end{array}$ \\
\hline
\end{tabular}

\begin{tabular}{|c|c|c|}
\hline & $\begin{array}{c}\text { 运风 } \\
\text { 险 }\end{array}$ & 风险。 \\
\hline \multirow{5}{*}{$\begin{array}{l}\text { 疫情 } \\
\text { 风险 }\end{array}$} & $\begin{array}{l}\text { 海关 } \\
\text { 查验 } \\
\text { 没收 } \\
\text { 风险 }\end{array}$ & $\begin{array}{l}\text { 海关对进口商品进行严格的病毒检 } \\
\text { 验, 一旦在进口商品上检测出病毒, } \\
\text { 商品会被退回或销毁处理。 }\end{array}$ \\
\hline & $\begin{array}{l}\text { 物流 } \\
\text { 运力 } \\
\text { 不足 } \\
\text { 风险 }\end{array}$ & $\begin{array}{l}\text { 由于海外疫情的不确定, 国际物流渠 } \\
\text { 道受阻, 清关检验压力增大, 物流廷 } \\
\text { 期或断航风险加大。 }\end{array}$ \\
\hline & $\begin{array}{l}\text { 商品 } \\
\text { 供应 } \\
\text { 链不 } \\
\text { 稳定 } \\
\text { 风险 }\end{array}$ & $\begin{array}{l}\text { 国内生产企业受疫情、原材料等多方 } \\
\text { 面影响, 具有停工停产风险。 }\end{array}$ \\
\hline & $\begin{array}{l}\text { 商品 } \\
\text { 成本 } \\
\text { 上升 } \\
\text { 风险 }\end{array}$ & 商品原材料价格上涨、人工费用上涨 \\
\hline & $\begin{array}{l}\text { 存货 } \\
\text { 风险 } \\
\text { 加大 } \\
\text { 风险 }\end{array}$ & $\begin{array}{l}\text { 受物流、供应链等多方面影响, 跨境 } \\
\text { 电商企业冏品库存风险增加。 }\end{array}$ \\
\hline
\end{tabular}

\section{4. 中美博弯期跨境电商企业风险评估}

\section{1 建立基于层次分析法（AHP）的风险评价 模型}

层次分析法 (AHP) 由美国运筹学家托马斯・塞蒂 在 20 世纪 70 年代提出, 通过定性和定量相结合的分 析方法系统的、层次化的解决多目标决策问题，在处 理复杂的决策问题时具有较高的实用性和有效性。层 次分析法将跟决策相关的因素分解成决策目标、中间 要素、备选方案等不同的层次结构, 通过求解判断矩 阵特征向量的办法取得各元素对比权重值, 最后进行 加权递阶归并计算出最终的目标方案权重, 层次分析 法 (AHP) 判断矩阵如图 1 所示。 ${ }^{[8]}$

$$
A=\left(\begin{array}{cccc}
a_{11} & a_{12} & \ldots & a_{1 m} \\
a_{21} & a_{22} & \ldots & a_{2 m} \\
\ldots & \ldots & \ldots & \ldots \\
a_{m 1} & a_{m 2} & \ldots & a_{m n}
\end{array}\right)
$$

图 1 层次分析法 (AHP) 判断矩阵

中美博亦期跨境电商项目风险包含两国的政治、 经济、营商环境等方面, 风险具有多目标性, 风险构 成因素众多，传统的风险分析方法只能对风险进行定 性分析, 无法将风险直观量化, 通过层次分析法将风 险进行量化综合评价, 有利于决策者了解和掌握。层 
次分析法的基本步骤主要包括: 构建层次结构模型、 构造判断矩阵、层次单排序和一致性检验、层次总排 序和一致性检验。利用层次分析法 (AHP) 进行风险定 量分析时构建的中美跨境电商项目风险评价层次模 型如图 2 所示:

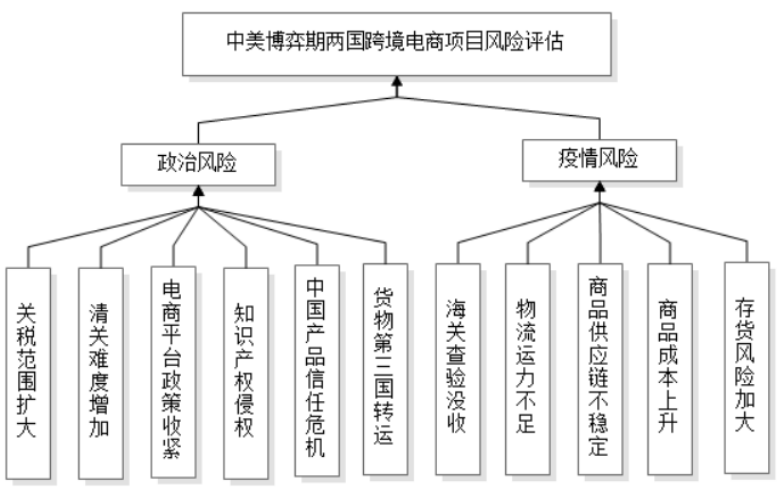

图 2 中美跨境电商项目风险评价层次模型

\section{2 基于层次分析法（AHP）的风险定量分析}

为了解决 AHP 手动计算的复杂性, 提高计算效率, 实现 Excel 调查表的自动生成、导入并进行群决策或 专家决策的自动化, 评价层次模型的建立及计算全部 通过 Yahhp (V 12.5.7528) 辅助软件进行。首先, 通过 Yahhp 软件建立如图 4.2 的风险评价层次模型; 然后, 通过软件生成 AHP 调查表功能生成 EXCEL 格式 的调查表, 将调查表发送给专家进行评价打分; 最后, 将收回的专家调查表导入 Yahhp 软件进行群决策计 算, 各专家权重为平均权重, 集结方式为计算结果集 结, 即分别计算各专家判断矩阵, 然后将计算得到的 排序权重均值作为集结结果, 最终得出算数平均权重 如表 2、表 3 所示。

表 2 中间层要素对决策目标的排序权重

\begin{tabular}{cc}
\hline 中间层要素 & 权重 \\
\hline 疫情风险 & 0.5556 \\
\hline 政治风险 & 0.4444 \\
\hline 表 3 方案层要素对决策目标的排序权重 \\
\hline 备选方案 & 权重 \\
\hline 关税范围扩大 & 0.1625 \\
\hline 海关查验没收 & 0.1425 \\
\hline 商品供应链不稳定 & 0.1341 \\
\hline 物流运力不足 & 0.1105 \\
\hline 商品成本上升 & 0.1015 \\
\hline
\end{tabular}

\begin{tabular}{cc}
\hline 清关难度增加 & 0.083 \\
\hline 货物第三国转运 & 0.0723 \\
\hline 存货风险加大 & 0.0669 \\
\hline 知识产权侵权 & 0.044 \\
\hline 电商平台政策收紧 & 0.0439 \\
\hline 中国产品信任危机 & 0.0388 \\
\hline
\end{tabular}

\section{5. 计算结果分析}

通过计算得出表 2, 当前中美之间跨境电商项目 疫情风险权重为 0.5556 , 政治风险权重为 0.4444 , 疫情风险权重略大于政治风险权重。从计算结果可以 看出, 参与评测的专家认为美国疫情对中美跨境电商 的影响略大于中美之间的政治风波影响, 这主要是由 于疫情以来美国疫情状况持续恶化, 没有任何好转和 收敛迹象, 截止 2021 年 1 月 10 日, 美国累计新冠死 亡病例已达 38.14 万人, 部分地区的感染率甚至超过 了 $20 \%$, 持续恶化的疫情严重打击了美国的经济发展, 最直接的表现是疫情期间美国 16 至 24 周岁年轻人群 的失业率居高不下, 最高时美国年轻群体的失业率达 到 $27 \%$, 高失业率导致美国年轻人群收入下降, 而美 国年轻群体是网上购物的主体, 低收入直接影响了跨 境电商的购买力。虽然美国采取了一些经济刺激措施, 例如：推出了积极的财政和货币政策，增加投资、出 口, 鼓励消费等, 但由于美国疫情形势依然严峻, 美 国未来的经济形势和前景依然不容乐观。

表 3 方案层中 11 项二级风险权重排序前五的分 别为关税范围扩大、海关查验没收、商品供应链不稳 定、物流运力不足和商品成本上升, 关税范围扩大属 于政治风险分类，其余四项属于疫情风险分类。从结 果可以看出, 评测专家认为对中美间跨境电商最长期、 最主要的影响是中美之间的政治关系, 对跨境电商最 直接的影响是关税。虽然, 美国大选已经落幕, 拜登 即将宣誓就职成为美国新一任总统, 新总统的上台自 然而然会给中美两国重新调整经贸关系提供机会和 空间, 这将有可能缓和中美之间的关系, 但美国的主 流民意一直都是反中和抗中, 美国总统是美国民意的 代言人, 所以中美之间未来的关系发展仍不明朗。尽 管美国很多官员提出加强中美之间关系, 扩大对华进 出口, 但在中美关系大的主线上, 中美之间激烈竞争 的态势不会改变，中美间总体趋势仍是对抗，中美间 贸易战会一直持续。

世界范围的新冠疫情对跨境电商项目物流、通关、 检疫、成本等也产生了巨大的影响。由于疫情, 国际 间物流航线变的不稳定，随时会因疫情管控停航，同 时导致物流成本不断上涨; 海关检疫更加严格, 一旦 检测出商品新冠病毒阳性, 商品会被退回或销毁; 由 于疫情的影响, 很多国内外商品生产厂商会因疫情防 
控要求停产, 导致商品供应链不稳定, 商品成本上涨。

\section{6. 风险应对措施}

中美间博弯将是长期的持续的过程，2020 年前 三季度，我国对美出口金额依然保持第一位，两国市 场在中美经贸关系高度政治化的背景下仍然发挥出 巨大的合作力量, 新冠疫情在一定程度上缓解了中美 之间的经贸压力，、凸显出全球化时代相互依赖的重 要性，中美之间的关系虽然从合作走向竞争，但彼此 间仍有巨大的合作机会和空间。作为跨境电商企业, 不能因为中美间的困难关系和新冠疫情影响就直接 放弃美国市场, 要学会管理风险和利用风险, 在危机 中把握机会。

虽然, 新冠疫情对各国的经济产生了影响, 但同 时, 新冠疫情培养了海外消费者的网购习惯, 对中国 传统外贸企业的数字化进程也起到了加速作用, 针对 疫情对跨境电商项目带来的冲击, 各电商企业要不断 完善自身商品的产业链和供应业链建设, 积极参与国 家跨境电商海外项目建设, 广泛开展与其他跨境电商 企业和外贸企业的合作, 共建共享海外仓, 规避疫情 对跨境电商国际物流和仓储的影响。积极开拓海外市 场, 促进内外贸一体化, 在不断提升中国制造商品品 质的同时要积极利用国内制造优势开发新商品品类, 重视宣传, 利用全球流行趋势提升商品的影响力, 例 如: 邀请国外网红在跨境电商平台直播带货; 利用云 平台的商品交易会向世界在线展示中国制造商品等, 使国外用户充分了解、依赖中国物美、质优、价廉的 商品。

针对中美两国的贸易摩擦, 美国对从中国进口商 品的报关查验会格外严格, 跨境电商平台受两国政策 影响会同步加大中国商品管理力度, 面对此种情况, 跨境电商企业应积极了解两国对外贸易政策和相关 法律法规, 建立完善的售前、售中、售后服务部门和 体系, 以两国法律为准绳, 合理合法的进行商品避税 及纠纷解决, 谨慎使用第三国转运方式进行商品避税, 为减少商品风险, 可选择国际保险公司投保相应险种, 进行商品风险转移。

\section{7. 结论}

中美两国由合作转为竞争关系是历史发展的必 然趋势, 中美两国间的博竕将是一个长期的持久的过 程, 跨境电商企业要学会利用风险识别的方法和工具
不断更新企业面临的高优先级风险，并制定相应对策 去管理和规避风险，将风险管理贯穿企业管理始终， 为跨境电商企业最终盈利提供保障。

\section{REFERENCES}

[1] Lu Xingfeng,Zhu Weiqun.Discussion on the prevention of adverse selection risk in cross-border e-commerce tax management [J/OL].Southwest Finance:1-10.

[2] Ju Yongmei. Risk identification and evaluation of cross-border e-commerce third-party logistics selection [J]. Commercial and economic research, 2020 ( 12 ) : $82-84$.

[3] Liu Yideng.Legal issues and normative guidance of cross-border e-commerce development [J].People s Forum, 2020 ( 26 ) : 100-102.

[4] Chen Yufen. Construction of quality risk assessment system for imported B2C cross-border e-commerce commodities based on whole process [J]. Commercial economy and management, 2019 ( 12 ) : 5-16.

[5] Wang Cong, Guo Xinyue, Zhang Yanping and Pan Xubin. Comparative study on risk management of imported mail quarantine at home and abroad [J]. Plant quarantine, 2019, 33 (06) : 45 - 48.

[6] Xue Chaogeng, Yan Mengna, Zhang Duo. Identification of risk factors of cross-border e-commerce ecosystem based on social network analysis [J]. Financial monthly, 2019 (16) : $113-119$

[7] Yang Mei, Wang Kaiyi, Shen Zhuo.The application of brainstorming method in risk identification of scientific research projects - - Taking the key technology research project of energy smart metering as an example [J].The Science and Technology Economic Guide, 2017 ( 04 ) : 7-8.

[8] Yu Meng.The internal control ability evaluation of FY company based on competency maturity model [ D ].Northeast University, 2018. 